Original Research Article

\title{
Drug utilisation pattern in dermatology outpatient department at a tertiary care hospital
}

\author{
G. N. S. Sangeetha Lakshmi*, Chilukuri Priyanka, Mortha Vineela
}

Department of Pharmacology, Osmania Medical College, Hyderabad, Telangana, India

Received: 09 September 2018

Accepted: 26 September 2018

\section{*Correspondence to:}

Dr. G. N. S. Sangeetha Lakshmi, Email: asangeethalakshmi@ yahoo.co.in

Copyright: (C) the author(s), publisher and licensee Medip Academy. This is an openaccess article distributed under the terms of the Creative Commons Attribution NonCommercial License, which permits unrestricted noncommercial use, distribution, and reproduction in any medium, provided the original work is properly cited.

\begin{abstract}
Background: Skin is the part of integumentary system that constitutes the largest organ of human body and thus it is exposed to injury by various extrinsic and intrinsic factors. The skin disorders have serious detrimental effect on quality of life of the general population. The present study was planned to define the prescription pattern in terms of rationality, drug interactions and financial burden of disease to the individual. Also, in the identification of problems related to drug use such as poly-pharmacy and drug-drug interaction.

Methods: The present study was conducted in the male and female out-patient Department of Dermatology at a Tertiary Care Hospital in Hyderabad, Telangana over a period of two months. Prescriptions of 400 patients were analyzed i.e. 200 each were taken from the male and female OPD patients. An observational and cross-sectional study design was adopted for this study.

Results: Prescriptions of 400 patients were analyzed. The average number of drugs per prescription was 3.73 in male OPD and 3.59 in female OPD. The percentage of generic drugs prescribed was $84.13 \%$ in male OPD and $77.3 \%$ in female OPD, drugs prescribed by brand name was $15.82 \%$ in male OPD and $22.7 \%$ in female OPD. Antihistamines were the most commonly prescribed drugs followed by antibacterial in female OPD and antifungals in male OPD.

Conclusions: Prescription of maximum drugs was by their generic name and was dispensed free of cost to the patients from the hospital pharmacy. Almost all the drugs prescribed as oral formulation were present in the NLEM, India 2011. Whereas some topical formulations prescribed are not present in the NLEM. Therefore, were prescribed by trade name. Regular educational interventions like sensitization on pharmacovigilance may further promote rational prescribing.
\end{abstract}

Keywords: Drug utilization, Dermatology, Male and female OPD, Prescribing pattern

\section{INTRODUCTION}

Skin is the part of integumentary system that constitutes the largest organ of human body and thus it is exposed to injury by various extrinsic factors such as environmental, chemical and infectious agents, as well as intrinsic factors such as metabolic, genetic and immunological. In addition to this, many systemic diseases are also identified by their dermatological manifestations thus it is said metaphorically as a mirror to various internal diseases. ${ }^{1,2}$ The skin disorders have serious detrimental effect on quality of life of the general population by increasing the suffering in terms of physical, social, psychological as well as it increases financial burden as most of the skin diseases are chronic and requires longer duration of treatment. ${ }^{3}$

As per WHO, Drug utilization studies or research are tools that deals with the marketing, distribution and prescription pattern of drugs and helps to assess the subsequent impact of these drugs on medical and socioeconomic status of patients. $^{4}$ Thus drug utilization studies helps in the understanding of prescription pattern as well as the quality of prescription in terms of rationality, drug interactions and financial burden of disease to the individual. Drug utilization studies are useful for obtaining information about drug use patterns and for identifying high cost drugs. ${ }^{5}$ Such analysis not only improves the standards of 
medical treatment at all levels in the health system, but also helps in the identification of problems related to drug use such as poly-pharmacy, drug-drug interaction, and adverse drug reaction. 6

The data regarding drug usage patterns in Dermatology in India are particularly lacking. Keeping these facts in consideration the present study was planned to define the pattern of drug use for the common skin conditions, their availability in the hospital pharmacy and to evaluate the cost analysis of each prescription in the Dermatology outpatient Department at Tertiary care hospital.

A prescription by a doctor is a reflection of physicians' attitude towards the disease and the role of drug in its treatment. The ultimate outcome of the dermatological prescription analysis gives a message to the prescribing physician to achieve rational and cost-effective medical care. ${ }^{7}$ It also provides an insight into the nature of health care at that facility.

The skin disorders constitute $2 \%$ of total Out Patient Department (OPD) consultations worldwide. ${ }^{8}$ However, no such data is available from India but still skin disorders in India are common and include pyoderma, acne, urticaria, dermatitis, scabies, fungal skin infections and alopecia etc. ${ }^{9}$ Prescription audit is an effective tool to constitute guidelines for improving drug utilization patterns and restricting irrational prescribing. ${ }^{5-7}$ Drug utilization studies improve standards of medical treatment at all levels in the health-care system.

Access to standardized and validated information on drug use is essential for assessing patterns of drug utilization. Identification of problems, access and educational or other interventions and monitoring the outcomes of interventions for the rational use of drugs. Drug utilisation research studies are important for policy making at national level as well as for individual patient management. But, in most of the middle or low income countries the availability of information on drug consumption is inadequate. This information is often lacking on even the broadest measures of drug use like the overall volume of use and total spend. ${ }^{10}$ But now the increasing availability of computerized databases that allow linkage of drug utilization data to diagnoses and outcomes are greatly facilitating the growth of drug utilization research.

Previous studies conducted in Australia suggest that academic detailing improves the quality of prescription and increases the adherence of clinician to standard treatment guidelines. ${ }^{11}$

The data regarding pattern of drug used in India, particularly in dermatology departments are very limited. This drug utilization study provides an insight to the prescriber regarding various issues related to polypharmacy, cost analysis and prevalent disease pattern in the region. ${ }^{12}$

\section{METHODS}

An observational and cross-sectional study design was adopted for this study. It was conducted over a period of two months June to July 2018. Oral Informed Consent was taken from all the patients before their prescriptions were analyzed. The present study was conducted in the Male and Female Outpatient Department of Dermatology at Tertiary a Care Hospital, Hyderabad. The hospital has a separate Male and Female OPD.

Prescriptions of 400 patients attending the dermatology OPD were analyzed. Out of the 400 prescriptions, 200 each were taken from the male and female OPD patients. Prescriptions were collected on two days in a week for a period of two months from June to July 2018. The variables assessed from the prescriptions included the demographic profile like male/female and age.

The relevant data recorded was diagnosis or pattern of skin disease. Various classes of drugs prescribed were recorded (antibiotics, antifungals, antiallergics, scabicides, emmolients, sunscreen lotion, steroids, keratolytic agents, moisturizers, or any other class) along with their dosage form, dose, frequency and duration of administration, average number of drugs prescribed per encounter, drugs prescribed by generic or brand name, average number of drugs prescribed from hospital pharmacy or outside pharmacy. Obtained information was then compiled and analyzed using World Health Organization (WHO) prescribing indicators, which included additional indices like commonest class/type of drugs prescribed and the various dosage form prescribed. ${ }^{13,14}$

The prescriptions were analysed with the help of descriptive statistics and results were expressed in percentage.

\section{Statistical analysis}

Data was entered and analyzed with Microsoft Excel 2007. Descriptive statistics were used to analyse the results. Percentage and averages of the variable were also calculated to compare the data with other findings.

\section{RESULTS}

In the demographic profile among 400 prescriptions, 200 were from Male OPD and 200 were from Female OPD. The age distribution and disease diagnosis of the patients is as shown in the Table 1 and 2 respectively.

Prescriptions given to 400 patients were analysed. The average number of drugs per prescription was 3.73 in male OPD and 3.59 in female OPD. The percentage of generic drugs prescribed was $84.18 \%$ in male OPD and $77.3 \%$ in female OPD, drugs prescribed by brand name was $15.82 \%$ in male OPD and $22.7 \%$ in female OPD as shown in Table 3. 
Table 1: Demography characteristics among study participants.

\begin{tabular}{|llc|l|}
\hline Variable & $\begin{array}{l}\text { Number } \\
\text { of patients }\end{array}$ & Hindus & Muslims \\
\hline Male & 200 & $99(50 \%)$ & $101(50 \%)$ \\
\hline Female & 200 & $64(32 \%)$ & $136(68 \%)$ \\
\hline Age (Years) & Males (\%) & Female (\%) \\
\hline $0-10$ Yrs & $4(2 \%)$ & $25(12.5 \%)$ \\
\hline $11-20$ Yrs & $52(26 \%)$ & $54(27 \%)$ \\
\hline $21-30$ Yrs & $60(30 \%)$ & $49(24.5 \%)$ \\
\hline $31-40$ Yrs & $37(18.5 \%)$ & $43(21.5 \%)$ \\
\hline $41-50$ Yrs & $16(8 \%)$ & $18(9 \%)$ \\
\hline $51-60$ Yrs & $18(9 \%)$ & $7(3.5 \%)$ \\
\hline $60-70$ Yrs & $10(5 \%)$ & $2(1 \%)$ \\
\hline $71-80$ yrs & $3(1.5 \%)$ & - \\
\hline
\end{tabular}

Table 2: Disease distribution among study participants.

\begin{tabular}{|lll|}
\hline Cases & Male & Female \\
\hline Tinea capitis & $2(1 \%)$ & $3(1.5 \%)$ \\
\hline Tinea corporis & $12(6 \%)$ & $13(6.5 \%)$ \\
\hline Tinea Cruris & $22(11 \%)$ & $11(5.5 \%)$ \\
\hline T. Corporis + T. Cruris & $41(20.5 \%)$ & $25(12.5 \%)$ \\
\hline Scabies & $15(7.5 \%)$ & $24(12 \%)$ \\
\hline Pruritis & $(0 \%)$ & $4(2 \%)$ \\
\hline Acne vulgaris & $19(9.5 \%)$ & $27(13.5 \%)$ \\
\hline Dermatitis & $14(7 \%)$ & $12(6 \%)$ \\
\hline Urticaria & $7(3.5 \%)$ & $9(4.5 \%)$ \\
\hline Alopecia & $5(2.5 \%)$ & $4(2 \%)$ \\
\hline Psoriasis & $4(2 \%)$ & $9(4.5 \%)$ \\
\hline Eczema & $11(5.5 \%)$ & $7(3.5 \%)$ \\
\hline Prurigo simplex & $3(1.5 \%)$ & $3(1.5 \%)$ \\
\hline $\begin{array}{l}\text { Chronic lichinephoid } \\
\text { eczema }\end{array}$ & $7(3.5 \%)$ & $0(0 \%)$ \\
\hline $\begin{array}{l}\text { PMLE: Polymorpho } \\
\text { light eruption }\end{array}$ & $4(2 \%)$ & $0(0 \%)$ \\
\hline Melasma & $2(1 \%)$ & $6(3 \%)$ \\
\hline Vitiligo & $1(0.5 \%)$ & $3(1.5 \%)$ \\
\hline Impetigo & $0(0 \%)$ & $2(1 \%)$ \\
\hline Lichen planus & $4(2 \%)$ & $4(2 \%)$ \\
\hline $\begin{array}{l}\text { PIN-post inflammatory } \\
\text { hyperpigmentation }\end{array}$ & $4(2 \%)$ & 0 \\
\hline Pityriasis versicolor & $7(3.5 \%)$ & 0 \\
\hline Macular amyloidosis & $4(2 \%)$ & 0 \\
\hline $\begin{array}{l}\text { FDE-fixed drug } \\
\text { eruption }\end{array}$ & $4(2 \%)$ & 0 \\
\hline Furuncle & $2(1 \%)$ & $1(0.5 \%)$ \\
\hline Folliculitis & $9(4.5 \%)$ & $1(0.5 \%)$ \\
\hline
\end{tabular}

In the prescriptions analysed from female OPD, oral formulations prescribed were 357 compared to 307 topical formulations as shown in Table 4 and 5. Among oral formulations antihistamines $142(40 \%)$ were the most common drugs prescribed shown in Figure 1.
Table 3: Analysis of prescriptions with respect to different parameters.

\begin{tabular}{|lll|}
\hline $\begin{array}{l}\text { Drug use } \\
\text { indicators }\end{array}$ & $\begin{array}{l}\text { Results } \\
\text { Male OPD }\end{array}$ & Female OPD \\
\hline $\begin{array}{l}\text { Total number of } \\
\text { drugs prescribed } \\
\text { in male OPD }\end{array}$ & 746 & 718 \\
\hline $\begin{array}{l}\text { Average number } \\
\text { of drugs per } \\
\text { prescription }\end{array}$ & $3.73(746 / 200)$ & $3.59(718 / 200)$ \\
\hline $\begin{array}{l}\text { Percentage of } \\
\text { drugs prescribed } \\
\text { by generic name }\end{array}$ & $\begin{array}{l}84.18 \% \\
(628 / 746)\end{array}$ & $77.3 \%(555 / 718)$ \\
\hline $\begin{array}{l}\text { Percentage of } \\
\text { drugs prescribed } \\
\text { by brand name }\end{array}$ & $\begin{array}{l}15.82 \% \\
(118 / 746)\end{array}$ & $22.7 \%(163 / 718)$ \\
\hline
\end{tabular}

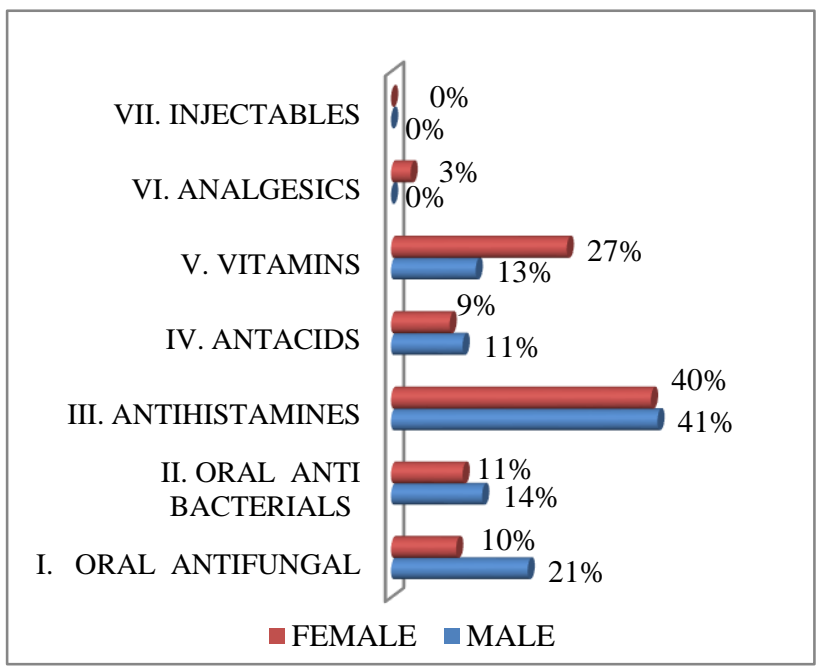

Figure 1: Percentage analysis of different classes of oral formulations drugs prescribed.

The first-generation antihistamines, 140 chlorpheniramine maleate were prescribed compared to 2 cetrizine. Antibacterial were the second most prescribed in both oral 40 (11\%) and topical 33 formulations. Among oral antibiotics tablet amoxycillin clavulanic acid 16 and tablet doxycycline 11 were prescribed. The other 11 antibiotics prescribed were $\mathrm{T}$ erythromycin. Among Topical antibiotics fusidic acid, soframycin and Whitfield's ointment (compound benzaic acid salicyclic acid ointment) were prescribed. Anti-fungal drugs were prescribed in both oral 36 as shown in Table 4 and topical formulations 84 . The oral antifungal agents prescribed were tablet griseofulvin1, fluconazole 5, sertaconazole 7 , others 7 i.e. itraconazole and terbinafine. The topical antifungal agents prescribed were clotrimazole, miconazole $2 \%$, sertaconazole nitrate $1 \%$ and luliconazole $1 \%$.

Topical steroids were prescribed more frequently than oral preparations. The topical steroids 35 prescribed were beta methasone $0.025 \%$ followed by fluticasone. The other oral 
formulations prescribed were antacids like T. ranitidine 33 (9\%), multivitamins 95 (27\%), B. complex, vitamin A and D, and C. Analgesics prescribed were $10(03 \%)$ like tablet paracetamol and only 1 injection was prescribed i.e. injection CPM $2 \mathrm{mg}$ as shown in Table 4.

Table 4: Analysis of different classes of oral formulation drugs prescribed.

\begin{tabular}{|lll|}
\hline Oral formulations chart & Male & Female \\
\hline Oral anti-fungal & $82(21 \%)$ & $36(10 \%)$ \\
\hline Oral anti-bacterials & $56(14 \%)$ & $40(11 \%)$ \\
\hline Antihistamines & $163(41 \%)$ & $142(40 \%)$ \\
\hline Antacids & $42(11 \%)$ & $33(09 \%)$ \\
\hline Vitamins & $50(13 \%)$ & $95(27 \%)$ \\
\hline Analgesics & $1(0 \%)$ & $10(03 \%)$ \\
\hline Injectables & $0(0 \%)$ & $1(00 \%)$ \\
\hline Total & $394(100 \%)$ & $357(100 \%)$ \\
\hline
\end{tabular}

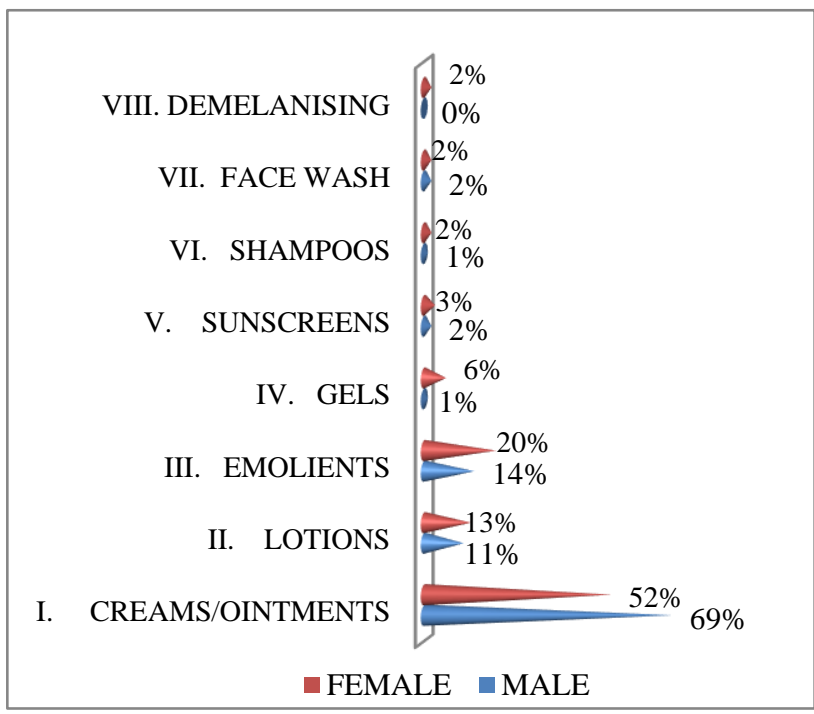

Figure 2: Percentage analysis of different classes of topical formulation drugs prescribed.

The topical formulation prescribed were Cutisoft cream and framycetin as creams/ointments 159 (52\%). The lotions $42(13 \%)$ prescribed were gamma benzene hexachloride (GBHC) 15 and permethrin 5 for scabies. Calamine 18, oscab lotion and habobetasol with salicyclic acid. The emolients prescribed was liquid paraffin 63 (20\%). The gels $18(6 \%)$ prescribed were deriina CMS, Aziderm and Benzac AC for acne. The sunscreen 9(3\%) prescribed were photoban, photostable SPF 50 and suncoat gel. The shampoos $5(2 \%)$ prescribed were scalpe and Inox $\mathrm{T}$ for dandruff. Face wash $5(2 \%)$ were advised i.e. salisic face wash. Demalanising agent $6(2 \%)$ given was kojoic acid shown in Table 5.

In the prescriptions analysed from male OPD, oral formulations prescribed were 394 compared to 316 Topical formulations. Antihistamines 163 (41\%) were the most commonly prescribed drugs shown in Table 4. The first generation antihistamines chlorpheniramine maleate 162 was prescribed compared to 2 cetirizine.

Antifungals were the second most commonly prescribed drugs in both oral 82 (21\%) and topical 142 formulations. The oral and topical antifungal drugs prescribed were the same as in prescriptions of female OPD.

Anti-bacterial drugs as oral formulations were $56(14 \%)$ as shown in Table 4 as compared to topical formulations 45. Tablet amoxycillin and clavulanic acid 24 as compared to doxycycline 15 . The other 17 antibiotics prescribed were tablet erythromycin. The topical steroids prescribed were 32 , i.e. more frequent than oral steroids.

Antacids 42 (11\%) were prescribed, vitamins 50 (13\%) and analgesic 1 . Injectables were not prescribed in male OPD. The antacids, vitamins and analgesics drugs prescribed were the same as in Female OPD.

The Topical preparations prescribed to patients in male OPD were similar to those prescribed in the female OPD. The topical preparations prescribed are shown in the Table 5.

\section{Table 5: Analysis of different classes of topical formulation drugs prescribed.}

\begin{tabular}{|lll|}
\hline \multicolumn{2}{l}{ Topical formulations chart } \\
\hline & Male & Female \\
\hline Creams/ointments & $221(69 \%)$ & $159(52 \%)$ \\
\hline Lotions & $35(11 \%)$ & $42(13 \%)$ \\
\hline Emolients & $43(14 \%)$ & $63(20 \%)$ \\
\hline Gels & $3(1 \%)$ & $18(06 \%)$ \\
\hline Sunscreens & $6(2 \%)$ & $9(03 \%)$ \\
\hline Shampoos & $2(1 \%)$ & $5(02 \%)$ \\
\hline Face wash & $5(2 \%)$ & $5(02 \%)$ \\
\hline Demelanising & $1(0 \%)$ & $6(02 \%)$ \\
\hline Total & $316(100 \%)$ & $307(100 \%)$ \\
\hline
\end{tabular}

\section{DISCUSSION}

A prescription by a doctor may be taken as an indication of the doctors' attitude towards the disease and the role of drugs in its treatment. Prescription is a written instruction given by a qualified medical practitioner with the intent to provide medicine or treatment for the benefit of the patient. Thus, the prescription in other words reflects the doctors knowledge and his attitude to treat the patient with due consideration of the patient's condition physically as well as financially. ${ }^{15}$ Availability and affordability are the two major determinants of a prescription and various other very important parameters are quality, rationality, completeness and cost per prescription. And one study that incorporates all these components is the drug utilization study. ${ }^{12}$ Till now very few drug utilization studies have been conducted in our institute and thus we did not have any comparable data of other studies from our institute. 
Thus, aim of the study was to help the dermatology prescriber in achieving rational and affordable treatment to their patients in terms of cost. This will also help in the mission of providing "Health care to all". ${ }^{16}$

In this study, the most common diagnosis was Tinea Corporis with Tinea Curis in male OPD 41 (20.5\%) and acne vulgaris $27(13.5 \%)$ in female OPD. The average number of drugs per prescription was 3.73 in male OPD and 3.59 in female OPD. The average number of drugs per prescription in our study is lower than the study conducted by Pathak in Patna i.e. 5.13. ${ }^{12}$ It is an important parameter while doing a prescription audit. Multiple drug prescribing results in poly-pharmacy. This may cause irrational prescribing and induce adverse effects. ${ }^{17}$

In this study, it can be seen that patients with varied diagnosis formed this study participants. Results of this study were in accordance with the study conducted by Vineeta et al, where the most common dermatological disorder was fungal and bacterial infections of the skin followed by eczema and dermatitis. ${ }^{18}$

Out of 746 drugs prescribed in male OPD, majority of drugs 628 (84.18\%) were prescribed by their generic name and the remaining $118(15.82 \%)$ were prescribed by their brand name. In the female OPD, out of 718 drugs, 555 $(77.3 \%)$ were prescribed by their generic name and the remaining $163(22.7 \%)$ were prescribed by their brand name. This finding was in accordance with the study conducted by Gambre R. ${ }^{19}$ In our hospital, the state government of Telangana supplies majority of the drugs prescribed in the OPD, free of cost to the patients in the hospital pharmacy, in generic form. The drugs are procured by the Telangana state drug control authority through tenders. Majority of the drugs prescribed in our study are included in the National Model List of Essential Medicines (NLEM) India, 2011 and were dispensed free of cost to the patients in generic form through the hospital pharmacy. Some topical preparations like betametazone, miconazole, framycetin ointments, emollients like liquid paraffin, lotions like calamine, GBHC and permethin, mentioned in NLEM were available in generic form with hospital pharmacy.

Some topical formulation drugs not in the NLEM like whitefields, sertaconazole nitrate and luliconazole ointment were also dispensed from the hospital pharmacy as generic drug. Drugs prescribed by brand name had to be purchased by the patient from medical store in the market. Most of the drugs prescribed by brand name were topical formulations like shampoo, demalanising agents, sunscreen lotions, face wash and gel (Derina CMS, Aziderm). In the study, the average cost of treatment per patient was not done as most of the drugs prescribed were dispensed to the patient free of cost in the hospital pharmacy.

In our study, in oral formulations, antihistamines were the most common class of drugs prescribed in male and female
OPD. ${ }^{12}$ Anti-bacterials were the second most common class of drugs in female OPD as acne vulgaris was the most common diagnosis. In male OPD, anti-fungals were the second most common class of drugs as T. Tinea Corporis with Tinea Cutis was the most common diagnosis. In this study, there was no deviation in the prescription of drugs like steroids, which can be harmful to the patients.

The study was done in a tertiary care hospital where the prescribing physician is a qualified dermatologist, which cannot reflect the health care facilities available in all health care centers particularly in rural areas.

Irrational drug prescription is a global problem among the physicians and solution has to come from the physicians himself as well as locally in form of appropriate policies and guidelines in accordance with WHO guidelines. Many strategies are being proposed, tested, and implemented to improve the quality of medication use. Opportunities for drug utilization research are still under-explored, but issues related to confidentiality of medical records and limitations in funding and personnel will determine the pace of growth of drug utilization research. ${ }^{20}$

It was a cross-sectional quantitative study with limited sample size. The study duration was short and the sample size was small, hence seasonal variation could influence the prescribing trend.

\section{CONCLUSION}

Prescription of maximum drugs was by their generic name and was dispensed free of cost to the patients from the hospital pharmacy, which is an encouraging sign and needs to be encouraged. Almost all the drugs prescribed as oral formulation were present in the NLEM, India 2011. Whereas some topical formulations prescribed were not present in the NLEM.

Therefore, were prescribed by trade name. Prescriptions encountered with injection were only 1 and prescription of steroids was less in the study populations. This is a very encouraging sign. Therefore, regular educational interventions like sensitization on pharmaco-vigilance by the pharmacology department in the medical college may further promote rational prescription.

\section{ACKNOWLEDGEMENTS}

Authors would like to thank faculty and Head of Department of Dermatology of the Institute for the permission, support and co-operation for the study. The authors would also like to thank the authorities of Osmania General Hospital, Hyderabad, India for their support.

\section{Funding: No funding sources \\ Conflict of interest: None declared}

Ethical approval: The study was approved by the Institutional Ethics Committee 


\section{REFERENCES}

1. Clark AF, Ghosh K, Tonnesen MG. Tissue Engineering for Cutaneous Wounds. J Investigative Dermatol. 2007;127:1018-29.

2. Engman MF. The skin: a mirror to the system. JAMA. 1919;73(21):1565-68.

3. Joel JJ, Jose N, Shastry CS. Patterns of Skin Disease and Prescribing Trends in Rural India. Sch Acad J Pharm. 2013;2(4):304-09.

4. Sjoqvist F, Birkett D. Introduction to Drug Utilization Research (WHO Booklet) New York: WHO Office of Publication; 2003. Drug utilization. In: Bramley DW, editor. 2003:76-79.

5. Lamichhane DC, Giri BR, Pathak OK, Panta OB, Shankar PR. Morbidity profile and prescribing patterns among outpatients in a teaching hospital in Western Nepal. MJM. 2006;9(2):126.

6. Cork MJ, Timmins J, Holden C, CARR J, Berry V, Tazi-Ahnini R, Ward SJ. An audit of adverse drug reactions to aqueous cream in children with atopic eczema. Pharmaceutical J. 2003;271(7277):747-8.

7. Dirk BR, Howard IM. Dermatologic pharmacology. In: Bertram G. Katzung (Eds.), Basic and clinical pharmacology. 10th ed. McGraw Hill Publications, Boston;2007:991-1008.

8. Saravanakumar RT, Prasad GS, Ragul G, Mohanta GP, Manna PK, Moorthi C. Study of prescribing pattern of topical corticosteroids in the department of dermatology in multi-speciality tertiary care teaching hospital in south India. Inj $\mathbf{J}$ Res Pharm Sci. 2012;3(4):685-87.

9. Gangadharan C, Joseph A, Sarojini PA. Pattern of skin diseases in Kerala. Indian J Dermatol Venereol Leprol. 1976;42:49-51.

10. ATC/DDD classification: drug utilization data constrains in developing countries. WHO Drug Inf. 2002;16:233-40. Available at: http://apps.who.int/medicinedocs/pdf/s4951e/s4951e. pdf. Accessed on June 28, 2013.

11. Markey P, Schattner P. Promoting evidence-based medicine in general practice-the impact of academic detailing. Fam Pract. 2001;18(4):364-66.
12. Pathak AK, Kumar S, Kumar M, Mohan L, Dikshit H. Study of drug utilization pattern for skin diseases in dermatology OPD of an Indian tertiary care hospitalA prescription survey. JCDR. 2016 Feb;10(2):FC01.

13. World Health Organization (WHO) and International Network for Rational Use of Drugs. How to Investigate Drug Use in Health Facilities: Selected Drug Use indicators. Geneva, Switzerland: WHO;1993. Available at: http://apps.who.int/medicinedocs/en/d/Js2289e/.

14. World Health Organization. Introduction to drug utilization research. Oslo, Norway: WHO;2003. Available at: http://apps.who.int/medicinedocs/en/d/ Js4876e.

15. Shankar RP, Partha P, Nagesh S. Prescribing patterns in medical outpatients. Int $\mathbf{J}$ Clin Pract. 2002;56(7):549-51.

16. Kumar AK, Chen LC, Choudhary M, Ganju S, Mahajan V, Sinha A, et al. Financing health care for all: challenges and opportunities. Lancet. 2011;377(9766):668-79.

17. Choudary DK, Bezbaruah BK. Prescribing pattern of analgesics in orthopedic in-patient department at tertiary care hospital in Guwahati, Assam, North East India. Indian J Parmacol. 2016;48:377-81.

18. Vineeta D, Sharad P, Ganachari MS, Geetanjali S, Santosh S. Assessment of drug prescribing patten and cost analysis for skin diseases in dermatological, department of tertiary care hospital: an international study. J Pharmacovig. 2016;4(3):1-6.

19. Gambre R, Khobragade A, Jalikar K, Patel S, Gaidhane S. Analysis of prescribing pattern of drugs among patients attending dermatology outpatient department of a tertiary care hospital. EJPMR. 2018;5(3):259-71.

20. Lee D, Bergman U. Studies of drug utilization. Pharmacoepidemiology. 1994;2:379-93.

Cite this article as: Sangeetha Lakshmi GNS, Chilukuri P, Vineela M. Drug utilisation pattern in dermatology outpatient department at a tertiary care hospital. Int J Basic Clin Pharmacol 2018;7:2101-6. 